\title{
Germline genome editing: public dialogue is urgent but not self- evident
}

\author{
Boy Vijlbrief ${ }^{1} \cdot$ Sam Riedijk ${ }^{1} \cdot$ Diewertje Houtman $^{1} \cdot$ Robert Hofstra $^{1}$
}

Received: 28 March 2019 / Revised: 13 June 2019 / Accepted: 3 July 2019 / Published online: 22 July 2019

(c) European Society of Human Genetics 2019

Chinese researcher Jiankui He claims to have edited the genome of two embryos which have been carried to term [1]. The twins are the first known children in the world carrying a gene edit in their germline. The experiment has attracted vehement criticism and condemnation from virtually all stakeholders in the germline genome editing debate. Experts have consented that safe and effective clinical application of germline genome editing (GLGE), if any, should be preceded by public dialogue. Such calls for dialogue often feature in constructive and valuable position statements regarding GLGE [2, 3]. However, the public character of GLGE is rarely made explicit. Here, we argue why GLGE is inherently a public issue, which in turn warrants public engagement, dialogue, and regulation. An important function of public engagement and dialogue is to keep the science accessible for the public, and to keep researchers accountable for their impact on society and the public at large. Public dialogue and engagement form the democratic basis to regulate clinical germline editing. Bearing this argument in mind, the call for public dialogue no longer risks sounding hollow.

Most straightforwardly, GLGE is an inherently public issue because it has the potential to strongly impact the public itself. For instance, preventing monogenetic disease by editing pathogenic gene variants may eventually decrease the frequency of such variants, and benefit the population at large. Likewise, the proliferation of edits with unpredictable or even dangerous side effects would also be borne by the population at large. Apart from such hypotheticals, there are more pressing arguments why GLGE is a deeply public matter. Borrowing terminology from economics, we classify the germline edits that result from GLGE as a public good.

Goods are defined as public when they are both nonrivalrous and non-excludable. If one individual using the good

\footnotetext{
Boy Vijlbrief

b.vijlbrief@erasmusmc.nl

1 Erasmus Medical Center, Rotterdam, the Netherlands
}

does not reduce its availability to others, the good is nonrivalrous [4]. Germline edits are non-rivalrous because edited individuals can procreate, and pass on their edited genes to the next generation. After several generations, many different individuals hailing from the originally edited person may concurrently have the same gene variant. Non-excludability entails individuals cannot be effectively excluded from use [4]. The off-spring of the originally edited person cannot be prevented from inheriting these edits, or from subsequent procreation. Thus, germline edits are a public good in an intergenerational context because they are both non-rivalrous and non-excludable. These characteristics strongly emphasize the inherently public nature of GLGE.

In addition, technology required for human germline editing has been developed with funding and tremendous effort from the public domain, by researchers employed by public institutions. Conversely, Jiankui He attracted private funding, failing to share his results, while gratefully employing methods developed with public means and infrastructure. As such, he has obscured all that should be up for public discussion, possibly on behalf of marketization or personal gain. In this way, achievements of public infrastructure and regulation risk appropriation by the private sector, resulting in erosion of the public infrastructure upon which the technology is built [5]. More importantly, this entails the privatization of the regulation and ethics of GLGE. This may strongly impair substantive public deliberation. However, privatization does not reduce the urgent need for public debate.

Taking all the aforementioned into account, there is a strong imperative to keep GLGE in the public realm. This opens the door for deliberation on how exactly public engagement can feed into regulation, and to what extent it requires the education of the public, gathering of opinions, and influence on governance (for example, as proposed by Jasanoff and Hurlbut [6] in their piece on a global observatory for GLGE). If anything, Jiankui He has painfully yet indisputably demonstrated that such public dialogue concerning GLGE is not self-evident. More importantly, he shows us that the time for public dialogue is now. 


\section{Compliance with ethical standards}

Conflict of interest The authors declare that they have no conflict of interest.

Publisher's note: Springer Nature remains neutral with regard to jurisdictional claims in published maps and institutional affiliations.

\section{References}

1. Dzau VJ, McNutt M, Bai C. Wake-up call from Hong Kong. Science. 2018;362:1215.
2. Ormond KE, Mortlock DP, Scholes DT, Bombard Y, Brody LC, Faucett WA, et al. Human germline genome editing. Am J Hum Genet. 2017;101:167-76.

3. de Wert G, Pennings G, Clarke A, Eichenlaub-Ritter U, van El CG, Forzano F, et al. Human germline gene editing. Recommendations of ESHG and ESHRE. Human Reproduction Open. 2018. https:// doi.org/10.1093/hropen/hox025

4. Anomaly J. Public goods and government action. Polit, Philos Econ. 2015;14:109-28.

5. Capps B, Chadwick R, Joly Y, Mulvihill JJ, Lysaght T, Zwart H. Falling giants and the rise of gene editing: ethics, private interests and the public good. Hum Genom. 2017;11:20.

6. Jasanoff S, Hurlbut JB. A global observatory for gene editing. Nature. 2018;555:435. 